\title{
Calcium channel blockade and survival in recipients of successful renal transplant: an analysis of the FAVORIT trial results
}

This article was published in the following Dove Press journal: International Journal of Nephrology and Renovascular Disease

\author{
Larry A Weinrauch ${ }^{1-4}$ \\ Jiankang Liu' \\ Brian Claggett ${ }^{\prime}$ \\ Peter V Finn' \\ Matthew R Weir ${ }^{5}$ \\ John A D'Elia ${ }^{2-4}$ \\ 'Cardiovascular Division, Brigham \\ and Women's Hospital, ${ }^{2}$ Kidney and \\ Hypertension Section, Joslin Diabetes \\ Center, ${ }^{3}$ Department of Medicine, \\ Beth Israel Deaconess Hospital, \\ ${ }^{4}$ Harvard Medical School, Boston, MA, \\ ${ }^{5}$ Division of Nephrology, Department \\ of Medicine, University of Maryland, \\ Baltimore, MD, USA
}

\begin{abstract}
Introduction: Single-center and observational studies have suggested that calcium channel blocking agents may decrease the expression of sepsis in individual populations. In the renal transplant population, a role for calcium channel blockers in allograft protection and in prevention of sepsis has been postulated. We hypothesized that any important survival benefit or risk related to chronic use of calcium channel blocking agents should be discernable through an analysis of a large database of stable recipients of renal allografts who had enrolled in a large international trial. Methods: A retrospective analysis of 4,110 renal transplant recipients who enrolled in the international Folic Acid for Vascular Outcome Reduction in Transplantation trial between 2002 and 2007 and were followed until 2010 was undertaken comparing cohorts (FAVORIT) of patients either taking $(n=1,436)$ or not taking $(n=2,674)$ calcium channel blocking medications. The endpoint was all-cause mortality (cardiovascular, noncardiovascular mortality, or unknown). Results were adjusted for country, age, race, sex, smoker, systolic blood pressure, diabetes mellitus, low-density lipoprotein, and chronic kidney disease status.
\end{abstract}

Results: There were no statistically significant differences in incidence rates of cardiovascular, noncardiovascular, and all-cause mortality between patients taking or not taking calcium channel blocking medications.

Conclusion: Although physiologic reasoning and small series results suggest a benefit for calcium channel blocking agents for allograft protection and sepsis prevention in immunosuppressed patients, we find no clear survival benefit in a large international renal transplant trial. Keywords: sepsis, immunosuppression, allograft survival, kidney transplant, calcium channel blockade, mortality

\section{Introduction}

Calcium channel blockers (CCBs) became popular in the 1980s and 1990s for patients who underwent renal or cardiac transplant as they raised cyclosporine levels and were associated with improved graft function. ${ }^{1-4}$ Although many clinical outcome trials of calcium channel blockade for prevention of cardiovascular events have been published, no large prospective trial has specifically addressed whether calcium channel blockade has any effect on noncardiovascular outcomes in patients who have undergone renal transplantation. In vitro and prior observational studies have suggested that the use of calcium channel blocking agents may decrease the expression of sepsis in resistant infections or enhance antibiotic effectiveness in differing nontransplant populations. ${ }^{5-17}$ Our retrospective study suggested a beneficial impact of calcium channel blocking agents on prevalence of sepsis in immunosuppressed transplant recipients, ${ }^{1}$ a population that has not been prospectively studied. We, therefore, performed a post hoc analysis of a large
Correspondence: Larry A Weinrauch Harvard Medical School, 52I Mount Auburn Street, Watertown,

MA 02472, USA

Tel + I 6179230800

Email Iweinrauch@hms.harvard.edu (c) (7) (5) 2018 Weinrauch et al. This work is published and licensed by Dove Medical Press Limited. The full terms of this license are available at https://www.dovepress.com/terms. BY php and incorporate the Creative Commons Attribution - Non Commercial (unported, v3.0) License (http://creativecommons.org/licenses/by-ncl/3.0/). By accessing the work you hereby accept the Terms. Non-commercial uses of the work are permitted without any further permission from Dove Medical Press Limited, provided the work is properly attributed. For
permission for commercial use of this work, please see paragraphs 4.2 and 5 of our Terms (https://www.dovepress.com/terms.php). 
prospective trial of renal transplant recipients ${ }^{18}$ to determine the difference in prevalence of cardiovascular, noncardiovascular (including infection related), and all-cause deaths between the two groups of patients, ie, those receiving CCB and those not.

\section{Hypothesis}

We hypothesized that any important survival benefit or risk related to the use of calcium channel blocking agents should be discernable through an analysis of a large database of stable recipients of renal allografts who had enrolled in a large international trial.

\section{Methods}

This is a retrospective analysis of the data set from the National Institutes of Health-funded International Folic Acid for Vascular Outcome Reduction in Transplant (FAVORIT, NCT 00064753) trial, which was designed to determine whether a combination of vitamins B6, B12, and folic acid would reduce both elevated homocysteine levels and cardiovascular endpoints in a large renal transplant recipient cohort. The full methods and results of this trial are reported elsewhere. ${ }^{18}$ Briefly, 4,110 patients were enrolled at 27 clinical sites which reported data from the baseline visit from August 2002 through January 2007. All were between 35 and 75 years of age, had elevated homocysteine levels ( $>11 \mathrm{~mol} / \mathrm{L}$ for women and $>12 \mathrm{~mol} / \mathrm{L}$ for men), and were at least 6 months after kidney transplant and with stable kidney function. Follow-up contacts occurred every 6 months through January 31, 2010 to obtain study-related outcomes through June 24, 2009.

For purposes of this investigation, all patients randomized and enrolled in the FAVORIT trial $(n=4,110)$ were classified as receiving or not receiving a calcium channel blocking agent (nondihydropyridine or dihydropyridine) at randomization into the study. Demographic information is listed in Table 1. There were 2,447 nondiabetic patients, 166 with Type 1 diabetes and 1,497 with Type 2 diabetes. All demographic listings, laboratory tests, and medication use are reported as of the baseline visit in the main study prior to randomization. Prescription medications taken regularly during the past month were recorded during participant interviews. Exclusion criteria included associated comorbidities that could be expected to limit survival (cancer, end-stage human immunodeficiency virus, hepatic, pulmonary, or cardiac disease) as well as recent ( $<3$ months) cardiovascular and renal events or surgical procedures.

History of cardiovascular events included the following classifications:

- Myocardial infarction or coronary artery revascularization (ie, coronary artery bypass surgery or angioplasty)
- Stroke (thromboembolic or hemorrhagic)

- Carotid arterial revascularization (endarterectomy or angioplasty)

- Abdominal or thoracic aortic aneurysm repair

- Renal arterial revascularization (bypass surgery or angioplasty)

- Lower extremity arterial revascularization (bypass surgery or angioplasty)

- Lower extremity amputation above the ankle.

Adjudicated events were prespecified and included the following:

- All-cause mortality

- Cardiovascular mortality

- Noncardiovascular mortality (pulmonary, malignancy, infection, trauma, surgery, suicide, renal, and others)

- Cardiovascular morbid events (nonfatal myocardial infarction or stroke, carotid, peripheral vascular or coronary revascularization).

All events were centrally adjudicated. For purposes of this analysis, only the first three categories are addressed.

\section{Statistical analysis}

Baseline data were summarized using either mean and SD or median and interquartile range for continuous variables and using count and percentage for categorical variables. Tests of equality between patients with versus without calcium channel blocker use were conducted using two-sample $t$-test, Wilcoxon rank-sum test and Pearson's $\chi^{2}$ test, respectively. Differences in risk for clinical outcomes associated with calcium channel blocker use were assessed via Kaplan-Meier curves as well unadjusted and adjusted Cox models. Adjusted models included age, race, sex, low-density lipoprotein cholesterol, smoking status, systolic blood pressure, diabetes, and chronic kidney disease class, and all Cox models were stratified by country (US, Canada, and Brazil); assessment of the proportional hazards assumption was conducted via test of Schoenfeld residuals. These relationships were then assessed within subgroups of patients according to their graft vintage. $p$-values less than 0.05 were considered significant. No adjustment was made for multiple comparisons. All analyses were conducted using STATA 14 (College Station, TX, USA).

\section{Results}

Table 1 lists the baseline demographics of the cohorts with respect to their use of calcium channel blocking agents. Thirty-six percent of the enrolled patients in this trial were 
Table I Baseline demographics by CCB use

\begin{tabular}{|c|c|c|c|}
\hline Baseline & $\begin{array}{l}\text { No } \\
(N=2,674)\end{array}$ & $\begin{array}{l}\text { Yes } \\
(N=I, 436)\end{array}$ & p-value \\
\hline Diabetes category & & & 0.008 \\
\hline No DM & 1,637 (6I.2\%) & $810(56.4 \%)$ & \\
\hline Type I & $108(4.0 \%)$ & $58(4.0 \%)$ & \\
\hline Type 2 & $929(34.7 \%)$ & $568(39.6 \%)$ & \\
\hline Immunotherapy (Immunosuppressants) & & & 0.09 \\
\hline $\mathrm{Cal}+\mathrm{BMS}+$ Pred & I,732 (64.8\%) & $963(67.1 \%)$ & \\
\hline Cal+Pred & $311(11.6 \%)$ & $176(12.3 \%)$ & \\
\hline BMS+Pred & 185 (6.9\%) & 87 (6.1\%) & \\
\hline $\mathrm{Cal}+\mathrm{BMS}$ & $165(6.2 \%)$ & $79(5.5 \%)$ & \\
\hline BMS+Sirol+Pred & $89(3.3 \%)$ & $35(2.4 \%)$ & \\
\hline Cal+Sirol+Pred & $80(3.0 \%)$ & $27(1.9 \%)$ & \\
\hline Other & $109(4.1 \%)$ & $69(4.8 \%)$ & \\
\hline Age (years) mean $\pm S D$ & $51.69 \pm 9.43$ & $52.36 \pm 9.45$ & 0.031 \\
\hline Non-White & $540(20.6 \%)$ & 405 (28.9\%) & $<0.001$ \\
\hline Country & & & $<0.001$ \\
\hline USA & I,915 (7I.6\%) & I,085 (75.6\%) & \\
\hline Canada & $312(11.7 \%)$ & $186(13.0 \%)$ & \\
\hline Brazil & $447(16.7 \%)$ & $165(11.5 \%)$ & \\
\hline Female & $\mathrm{I}, 076(40.2 \%)$ & $452(31.5 \%)$ & $<0.001$ \\
\hline Smoker (current) & $273(10.2 \%)$ & $178(12.4 \%)$ & 0.033 \\
\hline Prevalent CVD & $535(20.1 \%)$ & $285(20.0 \%)$ & 0.95 \\
\hline Hypertension & $2,342(87.6 \%)$ & $1,436(100.0 \%)$ & $<0.001$ \\
\hline Graft vintage (years) median (interquartile ranges) & $4.0(1.7,7.4)$ & $4 . I(1.6,7.6)$ & 0.75 \\
\hline \multicolumn{4}{|l|}{ Allograft source } \\
\hline Nonliving & I,488 (55.6\%) & $883(61.5 \%)$ & $<0.001$ \\
\hline Living & I, 168 (43.7\%) & $537(37.4 \%)$ & $<0.001$ \\
\hline BMI $\left(\mathrm{kg} / \mathrm{m}^{2}\right)$ mean $\pm \mathrm{SD}$ & $29.08 \pm 6.33$ & $29.34 \pm 6.06$ & 0.21 \\
\hline Creatinine $(\mathrm{mmol} / \mathrm{L})$ mean $\pm \mathrm{SD}$ & $1.62 \pm 0.46$ & $1.65 \pm 0.50$ & 0.040 \\
\hline eGFR $(\mathrm{mL} / \mathrm{min})$ mean $\pm \mathrm{SD}$ & $48.42 \pm 15.63$ & $49.43 \pm 17.18$ & 0.06 \\
\hline CKD & & & 0.08 \\
\hline GFR $\geq 90$ & 38 (I.5\%) & $31(2.2 \%)$ & \\
\hline $60 \leq$ GFR $<90$ & $511(19.5 \%)$ & $308(22.0 \%)$ & \\
\hline $30 \leq \mathrm{GFR}<60$ & I,818 (69.4\%) & $920(65.7 \%)$ & \\
\hline $15 \leq$ GFR $<30$ & $252(9.6 \%)$ & $142(10.1 \%)$ & \\
\hline GFR $<15$ & $\mathrm{I}(0.0 \%)$ & $0(0.0 \%)$ & \\
\hline Cholesterol $(\mathrm{mg} / \mathrm{dL})$ mean $\pm \mathrm{SD}$ & $184.25 \pm 43.93$ & $\mid 85.21 \pm 44.14$ & 0.51 \\
\hline Triglycerides $(\mathrm{mg} / \mathrm{dL})$ mean $\pm \mathrm{SD}$ & $198.64 \pm 199.92$ & $198.97 \pm 143.79$ & 0.96 \\
\hline $\mathrm{HDL}$ cholesterol $(\mathrm{mg} / \mathrm{dL})$ mean $\pm \mathrm{SD}$ & $45.93 \pm 13.49$ & $46.81 \pm 14.70$ & 0.06 \\
\hline LDL cholesterol $(\mathrm{mg} / \mathrm{dL})$ mean $\pm \mathrm{SD}$ & $100.48 \pm 34.15$ & $100.34 \pm 33.38$ & 0.90 \\
\hline Homocysteine (mol/L) mean \pm SD & $15.69 \pm 6.70$ & $16.60 \pm 8.13$ & 0.010 \\
\hline \multicolumn{4}{|l|}{ Cardiovascular history } \\
\hline Prior MI/CHD & $378(14.2 \%)$ & $188(13.2 \%)$ & 0.38 \\
\hline Prior stroke/CBVD & $179(6.7 \%)$ & $92(6.4 \%)$ & 0.74 \\
\hline Prior AAA repair/leak & 103 (3.9\%) & $60(4.2 \%)$ & 0.59 \\
\hline Prior CVD (any) & $535(20.1 \%)$ & $285(20.0 \%)$ & 0.95 \\
\hline Prior renal revascularization & 145 (5.4\%) & $76(5.3 \%)$ & 0.89 \\
\hline Prior amputation & $68(2.5 \%)$ & $42(2.9 \%)$ & 0.47 \\
\hline
\end{tabular}

Abbreviations: CBVD, cerebrovascular disease, Cal, calcineurin inhibitors; Sirol, sirolimus; BMS, bone marrow suppressants; Pred, prednisone; CCB, calcium channel blocker; DM, diabetes mellitus; LDL, low-density lipoprotein; HDL, high-density lipoprotein; eGFR, estimated glomerular filtration rate; CHD, coronary heart disease; CKD, chronic kidney disease; BMI, body mass index; MI, myocardial infarction; AAA, abdominal aortic aneurysm; CVD, cardiovascular disease.

receiving calcium channel blocking agents at entry into the study. CCB use was statistically more common among patients who listed themselves as non-White, had hypertension, were recipients of allografts from nonliving donors, or had Type 2 diabetes. The use of calcium channel blocking agents was higher in patients receiving calcineurin inhibitors. Females, patients in Brazil, and individuals with live-related allografts were less likely to be receiving calcium channel 
blocking agents. Interestingly, cardiovascular history did not appear to be associated with CCB usage.

Table 2 lists the noncardiovascular and cardiovascular mortality over the course of the FAVORIT study. Event rates are described by number, percentage, and per 100 patient years of follow-up and are reported as unadjusted and adjusted hazard ratios for other clinical factors. The CIs for all causes of death crossed unity, and there appear to be no differences in the noncardiovascular or cardiovascular mortality based upon baseline use of CCBs. Cardiovascular, noncardiovascular, and all-cause mortality during the study were not impacted by calcium channel blockade whether pre-existent cardiovascular disease was present or absent.

Figure 1 illustrates the observation that patient survival curves during FAVORIT were not impacted by calcium channel blocking agent use at baseline. Figure 2 focuses on organ survival rates (death censored) and demonstrates that the use of calcium channel blocking agents at baseline did not result in better graft organ success.

\section{Discussion}

Although there has been considerable interest in blocking of calcium channels for the control of various multidrug resistant infectious diseases including malaria, schistosomiasis, tuberculosis, and inflammatory responses, ${ }^{5-17}$ our retrospective analysis of this large renal transplant trial database does not provide any support for the hypothesis that calcium channel blocking agent use provides protection from infectious, all-cause, or cardiovascular mortality. A recent study also demonstrated that calcium sensitizing agents would not improve organ dysfunction in sepsis. ${ }^{19}$ Calcium channel blocking agents may be useful in control of hypertension, rate control in atrial fibrillation, and perhaps in prevention of graft rejection when prescribed pre- or early postrenal allograft. Despite early positive observational reports, there appears to be no compelling evidence to support long-term use of calcium channel blockade for a purely survival benefit in this population. While other databases may be available for similar populations that may confirm or extend our observations, they have not yet reported outcomes related to calcium blockade use. No similar outcome data are available for other populations of chronically immunosuppressed due to other nonrenal solid organ transplantation or other underlying disease. Although our analysis is retrospective, and may have an indication bias for use of calcium channel blockade, given the size of the trial, its results, and prior negative trials with respect to cardiovascular outcomes in kidney transplant

Table 2 Effect of baseline use of calcium channel blockade on noncardiovascular, cardiovascular, and all-cause mortality in the FAVORIT trial

\begin{tabular}{|c|c|c|c|c|}
\hline \multirow[t]{2}{*}{ Outcome } & \multicolumn{2}{|c|}{$\begin{array}{l}\text { Number and } \% \text { of participants with } \\
\text { event, and incidence rate } \\
\text { per- } 100 \text { person-year (py) }\end{array}$} & \multirow{2}{*}{$\begin{array}{l}\text { Unadjusted model }{ }^{a} \\
\text { HR (Yes vs No), } \\
95 \% \text { Cl, } \text { p-value }\end{array}$} & \multirow{2}{*}{$\begin{array}{l}\text { Adjusted model } \\
\\
\text { HR (Yes vs No), } \\
95 \% \text { Cl, p-value }\end{array}$} \\
\hline & No & Yes & & \\
\hline Any noncardiovascular death & I 79 (6.7\%), I.7 & 107 (7.5\%), I.8 & I.08 (0.85-I.37), 0.54 & 0.99 (0.76-1.30), 0.96 \\
\hline $\mathrm{PH}$ test & & & 0.044 & 0.11 \\
\hline Death (I, P, M) & I 28 (4.8\%), I.2 & $87(6.1 \%), 1.5$ & $1.22(0.93-1.6 I), 0.15$ & I.I 6 (0.85-I.57), 0.35 \\
\hline $\mathrm{PH}$ test & & & 0.12 & 0.22 \\
\hline Death (S, P, M, R, I) & I 36 (5.1\%), I.3 & 93 (6.5\%), I.6 & $1.23(0.95-1.6 I), 0.12$ & I. $I 7$ (0.87-I.57), 0.3 I \\
\hline PH test & & & 0.12 & 0.24 \\
\hline Suicide & 0 (0.0\%), 0.0 & $2(0.1 \%), 0.0$ & - & - \\
\hline Pulmonary & I 4 (0.5\%), 0.1 & $12(0.8 \%), 0.2$ & I.56 (0.72-3.37), 0.26 & $1.88(0.78-4.58), 0.16$ \\
\hline PH test & & & 0.03 & 0.61 \\
\hline Malignancy & 48 (I.8\%), 0.5 & $28(2.0 \%), 0.5$ & 1.05 (0.66-I.67), 0.85 & $0.93(0.56-1.55), 0.77$ \\
\hline $\mathrm{PH}$ test & & & 0.39 & 0.87 \\
\hline Infection & 66 (2.5\%), 0.6 & 47 (3.3\%), 0.8 & 1.29 (0.88-1.87), 0.19 & I.23 (0.80-I.88), 0.35 \\
\hline $\mathrm{PH}$ test & & & 0.72 & 0.68 \\
\hline Renal & $8(0.3 \%), 0.1$ & $4(0.3 \%), 0.1$ & $0.91(0.27-3.02), 0.88$ & $0.73(0.66-3.06), 0.66$ \\
\hline PH test & & & 0.26 & 0.17 \\
\hline Any cardiovascular death & I I 5 (4.4\%), I.I & 76 (5.4\%), I.3 & $1.20(0.90-1.60), 0.22$ & I.2I (0.88-I.65), 0.24 \\
\hline All-cause mortality & 305 (I I.4\%), 2.9 & 188 (13.1\%), 3.2 & I.II (0.93-I.33), 0.25 & $1.06(0.86-1.29), 0.59$ \\
\hline
\end{tabular}



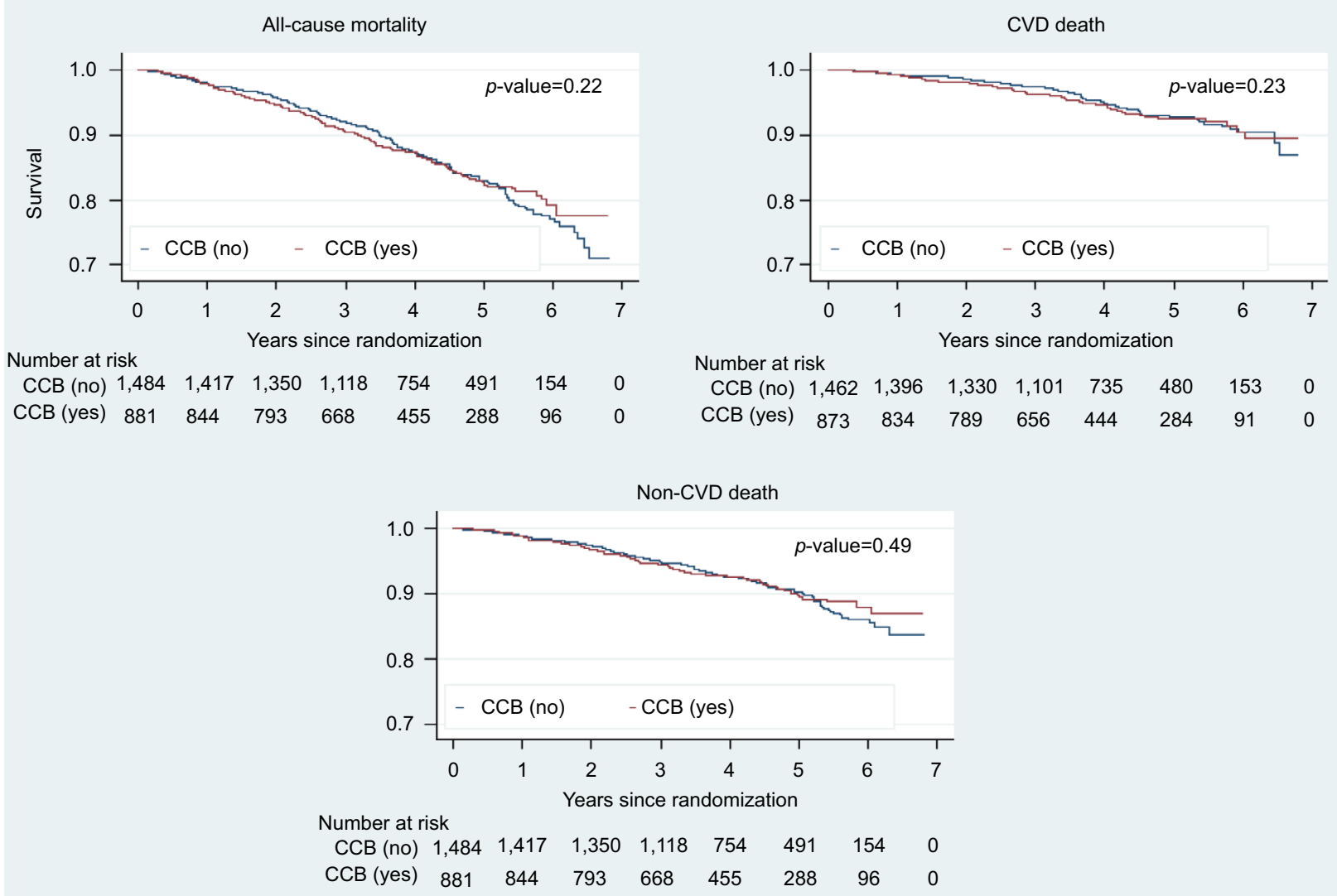

Figure I The effect of baseline CCB use in kidney transplant recipients: Kaplan-Meier patient survival curves.

Abbreviations: CVD, cardiovascular disease; CCB, calcium channel blocker.

patients, it is unlikely that additional trials of calcium channel blockade for survival benefit will be financially supported to address this issue.

\section{Limitations}

As the FAVORIT study was designed to test the hypothesis that cardiovascular outcomes might be improved by reduction in elevated homocysteine, our retrospective analysis focuses not only on cardiovascular mortality but also noncardiovascular mortality, centrally adjudicated as primarily due to noncardiovascular causes such as infection, pulmonary, malignancy, trauma, surgery, suicide, or renal. The records reviewed did not address the reasons for the initial prescription of the calcium channel blocking agent, dosage, duration of use, or whether they were continued during the study. Therefore, any changes in blood pressure management (crossover by new CCB prescription, elimination), or resultant blood pressure during the study cannot be analyzed. Females were less likely to receive CCBs. There were no significant differences noted between groups with respect to prior history of cardiovascular disease, body mass index, duration of functioning allograft, or allograft function. As would be expected, the group receiving CCBs was more likely to have a diagnosis of hypertension. While one can never totally exclude an indication bias (sicker patients receiving $\mathrm{CCBs}$ ), the data suggest that regional variation and gender played a role in CCB usage, but prior cardiovascular events and graft function did not. Patient or physician preference can also not be excluded as a reason for prescription of calcium channel blockade. We find the fact that the use of CCBs comported no excess survival risk quite reassuring. No central record was available for nonfatal infectious or septic episodes; therefore, possible effects of calcium channel blockade on expression of nonfatal infections and/or sepsis cannot be excluded.

Despite these methodologic limitations, this is the largest transplant study in which such an analysis was possible. Although we did not detect a signal for survival advantage for calcium channel blockade, there is no data to suggest that these agents, which are effective in lowering blood pressure, caused harm. It is possible that those who received them 


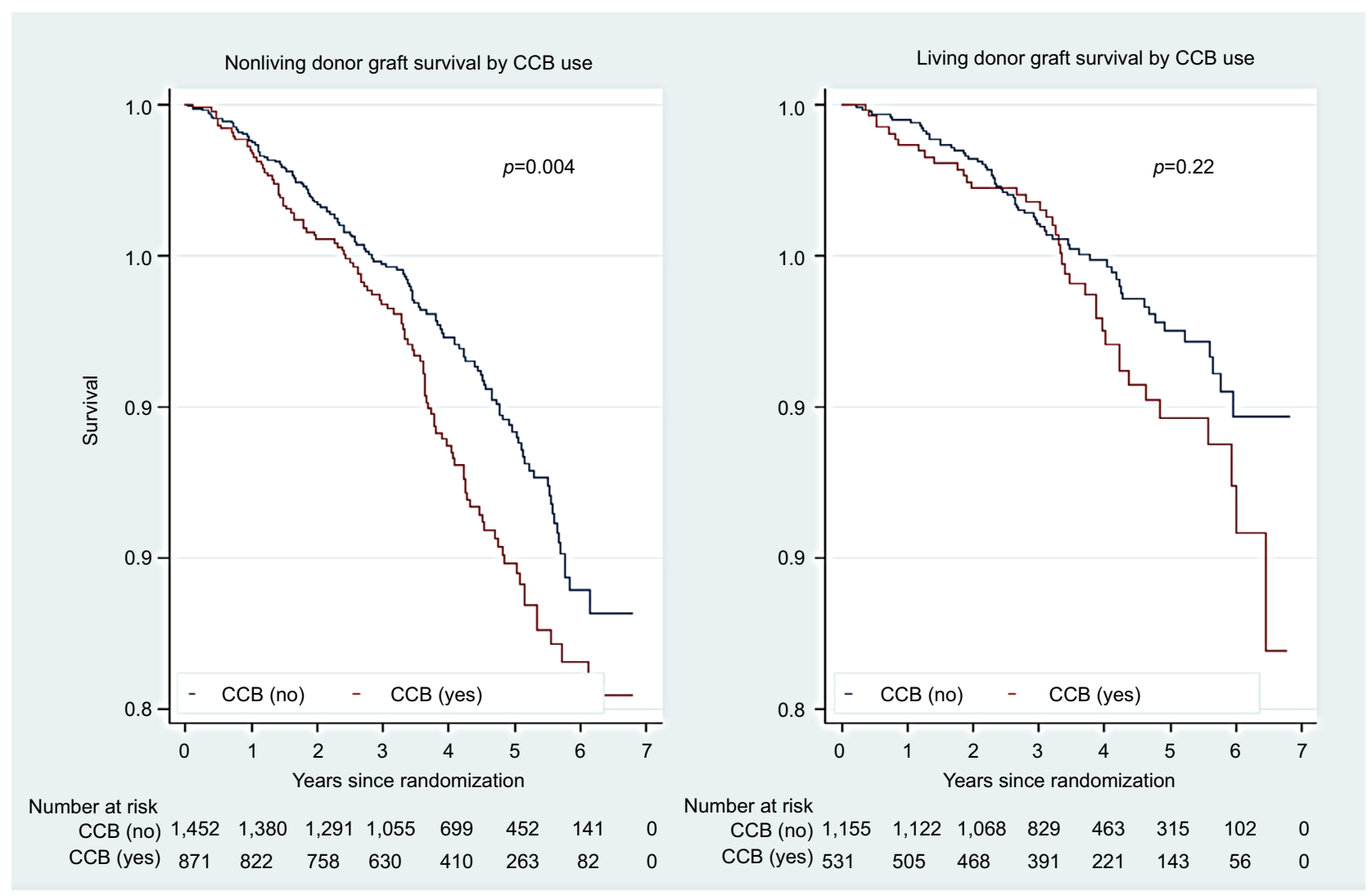

Figure 2 The effect of baseline CCB use in kidney transplant recipients: Kaplan-Meier allograft survival curves.

Abbreviation: $\mathrm{CCB}$, calcium channel blocker.

indeed had more resistance to antihypertensive agents and would have had worse results without their use. Our comments regarding usage of these medications are limited to allcause mortality and not efficiency of blood pressure lowering.

\section{Conclusion}

Calcium channel blocking medications are often used after solid organ transplantation, predominantly for blood pressure control. This retrospective analysis of a large international trial does not demonstrate any signal of excess risk or survival benefit associated with the use of calcium channel blocking agents in patients who have undergone successful renal allograft transplantation. Possible effects of calcium channel blockade on expression of nonfatal infections and/or sepsis cannot be excluded and will require additional research on lower cost generic medications that may serve as adjunctive therapy for resistant infections. ${ }^{20}$

\section{Author contributions}

All authors contributed toward data analysis, drafting and critically revising the paper and agree to be accountable for all aspects of the work.

\section{Disclosure}

The authors report no conflicts of interest in this work.

\section{References}

1. Weinrauch LA, D'Elia JA, Gleason RE, Shaffer D, Monaco AP. Role of calcium channel blockers in diabetic renal transplant patients: preliminary observations on protection from sepsis. Clin Nephrol. 1995;44:185-192.

2. Jacobsson J, Odlind B, Tufveson G, Wahlberg J. Improvement of renal preservation by adding lidoflazine to University of Wisconsin solution. An experimental study in the rat. Cryobiology. 1992;29:305-309.

3. Chrystostomu A, Walker RG, Russ GR, D'Apice AJF, Kincaid-Smith I, Mathew TH. Diltiazem in renal allograft recipients receiving cyclosporine. Transplantation. 1993;55:300-304.

4. Kuypers DR, Neumayer HH, Fritsche K, Rodicio JL, van Trentergen Y; Lacipine study group. Calcium channel blockade and preservation of renal graft function in cyclosporine-treated recipients: a prospective randomized placebo-controlled 2-year study. Transplantation. 2004;78:1204-1211.

5. Pletz MW, Michaylov N, Schumacher U, et al. Antihypertensives suppress the emergence of flouroquinolone-resistant mutants in pneumococci: an in vitro study. Int J Med Microbiol. 2013;303:176-181.

6. Song L, Cui R, Yang Y, Wu X. Role of calcium channels in cellular anti-tuberculosis effects: potential of voltage - gated calcium-channel blockers in tuberculosis therapy. J Microbiol Immunol Infect. 2015;48: 471-476.

7. Scheibel LW, Colambani PM, Hess AD, Aikawa M, Atkinson T, Milhous WK. Calcium and calmodulin antagonists inhibit human malaria parasites (Plasmodium falciparum): implications for drug design. Proc Nat Acad Sci USA. 1987;84:7311-7314. 
8. Martins YC, Clemmer L, Orjuela-Sanchez P, et al. Slow and continuous delivery of a low dose of nimodipine improves survival and electrocardiogram parameters in rescue therapy of mice with experimental cerebral malaria. Malaria J. 2013;12:138-154.

9. Gryseels B, Mbaye A, DeVias SJ, et al. Are poor responses to praziquantel for treatment of Schistisoma mansoni infections in Senegal due to resistance? An overview of the evidence. Trop Med Int Health. 2001;6:864-873.

10. Silva-Moraes V, Couto FF, Vasconcelos MM, et al. Antischistosomal activity of a calcium channel antagonist on schistosomula and adult schistosoma Mansoni worms. Mem Inst Oswaldo Cruz. 2013;108: 600-604.

11. Weir MR. Therapeutic benefits of calcium channel blockers in cyclosporine-treated organ transplant recipients: blood pressure control and immunosuppression. Am J Med. 1991;90:32S-36S.

12. Dial S, Nessim SJ, Kezouh A, Benisty J, Suissa S. Antihypertensive agents acting on the renin-angiotensin system, and the risk of sepsis. Br J Clini Pharmacol. 2014;78:1151-1158.

13. Zeng L, Hunter K, Gaughan J, Podder S. Preadmission use of calcium channel blockers and outcomes after hospitalization with pneumonia: a retrospective propensity-matched cohort study. Am J Therap. Epub 2015 Aug 13.
14. Tarlowe MH, Duffy A, Kannan KB, et al. Prospective study of neutrophil chemokine responses in trauma patients at risk for pneumonia. Am J Resp Critic Care Med. 2005;171:753-759.

15. Meldrum DR, Ayala A, Chaudry IH. Mechanism of diltiazem's immunomodulatory effects after hemorrhage and resuscitation. Am J Physiol. 1993;265:C412-C421.

16. Rose S, Baumann H, Tahqeis GP, Sayeed MM. Diltiazem and superoxide dismutase modulate hepatic acute phase response in gram-negative sepsis. Shock. 1994;1:87-93.

17. D'Elia JA, Gleason RE, Monaco AP, Weinrauch LA. Does calcium channel blockade have a role in prevention of expression of sepsis in renal transplant recipients? Int J Nephrol Renovasc Dis. 2016;9:291-295.

18. Bostom AG, Carpenter MA, Kusek JW, et al; FAVORIT Investigators. Rationale and design of the Folic Acid for Vascular Outcome Reduction In Transplantation (FAVORIT) trial. Am Heart J. 2006;152(3):448. e1-e7.

19. Gordon AC, Perkins GD, Singer M, et al. Levosimendan for the prevention of acute organ dysfunction in sepsis. N Engl J Med. 2016;375: 1638-1648.

20. Weinrauch LA, D'Elia JA. The fight against multidrug-resistant bacteria. Ann Intern Med. 2017;166(1):77-78.
The International Journal of Nephrology and Renovascular Disease is an international, peer-reviewed open access journal focusing on the pathophysiology of the kidney and vascular supply. Epidemiology, screening, diagnosis, and treatment interventions are covered as well as basic science, biochemical and immunological studies. The manuscript management system is completely online and includes a very quick and fair peer-review system, which is all easy to use. Visit http://www. dovepress.com/testimonials.php to read real quotes from published authors. 